\title{
Cognitive Training in Soccer: Where Is the Key Point?
}

\author{
Matteo Giuriato ${ }^{1}$, Nicola Lovecchio ${ }^{2}$ \\ ${ }^{1}$ Department of Human Science, Università di Verona, Verona, Italy \\ ${ }^{2}$ Department Biomedical Science for Health, Università degli Studi di Milano, Milano, Italy \\ Email: nicola.lovecchio@unimi.it
}

How to cite this paper: Giuriato, M. and Lovecchio, N. (2018) Cognitive Training in Soccer: Where Is the Key Point? Open Access Library Journal, 5: e4333. https://doi.org/10.4236/oalib.1104333

Received: January 12, 2018

Accepted: February 6, 2018

Published: February 9, 2018

Copyright (c) 2018 by authors and Open Access Library Inc.

This work is licensed under the Creative Commons Attribution International License (CC BY 4.0).

http://creativecommons.org/licenses/by/4.0/

\begin{abstract}
Cognitive skills and executive function, in the last years become a golden reference to increase attention social skills and sport success. In particular, soccer is an open skills sport that requires a constant demand of cognitive skills and executive function because the unstable environment defines the decision making. Thus, modern soccer trainer changes the approach avoiding massive conditional exercises and introducing small side games. The purpose of this paper is to investigate what the cognitive training is and what could be an adequate stimulation to improve the executive function in soccer player.
\end{abstract}

\section{Subject Areas \\ Sports Science}

\section{Keywords}

Executive Function, Cognitive Function, Soccer, Decision Making

\section{Introduction}

The training process in soccer game focused on tactic and technique learning [1] [2] and when the player reached the pubertal period, also, on conditional skills [3]. In recent years researchers and trainers shifted the attention on other aspects of the game: the cognitive function. Indeed, the cognitive approach to the training became widely used [4] [5] evolving the idea of game: the promotion of high cognitive function and not only excellent condition skills. The authors agreed with this new global approach to the training because soccer is an open skill sport, where the players have to make decision quickly during unstable, unpredictable and externally paced environment. Indeed, the success in soccer de- 
pends on how informations are processed considering the complex and quickly changing environment [6] [7]. This close relation between the environment and the decision of the players leads the coaches to train towards "plastic" players. Thus, the cognitive training becomes the solution for young players, even through executive function [7] [8]. Executive Functions (EF; also called executive control or cognitive control [9]), in fact, regard the usual top-down mental processes applied when people keep the concentration and pay attention, when going on automatically or relying on instinct or intuition that would be ill-advised, insufficient, or impossible [3]. Particularly, there are three cores of EF [9]: inhibition and interference control (selective attention and cognitive inhibition), working memory and cognitive flexibility [9].

In other words, EF are an "umbrella term" that involves the complex cognitive processes required to perform novel or difficult goal-directed tasks [10]. In practice, considering the human movements, EF are based on the ability to plan the action before the realization and the ability to predict the potential effects of specific actions. These functions are essential for mental and physical health [9]; for academic success [11]; for cognitive or psychological development [12] and then for social appreciation [9]. Thus they need an earlier development process during childhood [9] [13] using stimulus for problem-solving experiences, planning of events and association of concepts [14].

In this point, the sport (in particular the open skills sport competition) seems to be a full experience to improve EF or those mainly implicated: any competition is a continuum of problem-solving situations that requires constant planning in relation to a speedy prediction of opponent intention. Thus the purpose of this report was to bring emphasis on the significance of EF in soccer game among literatures.

\section{State of Art}

A recent revision about EF suggested that within different physical activities (traditional martial arts, yoga, or aerobics activity) we could find positive outcomes on cognitive activity during childhood [9] while an experimental soccer program determined improvements on EF because requires prospective control, perceptual skill and motor coordination [13]. Even if, the objective quantification of cognitive outcomes is hard to realize it is indirectly assessed using the concepts of EF [15], some studies were focused on their importance in soccer. In point of this, for example, the Spanish federation, suggested the crucial role of small sides games with different options: improving the number of target-goal, competition with different numbers of players divided in the two team and restriction of vision (one eye, or shadow the ball in some routines) [1] [2] [16]. These last suggestions are in line with the visual restricted training with stroboscopic eyewear that improved the dribbling performance [4] and underline the crucial relevance of vision in sport as suggested by Miller \& Clapp [17].

Within these original practices, become important accentuate the effects of 
mental fatigue influences on both offensive and defensive technical performance [18]. Indeed, mental fatigue is due to the greater mental effort required to substain attention and inhibition "against" the stimulus as a natural relation with the environment [19] (see the Figure 1).

Myer et al. [20], in addition, provided a rationale for the importance to differentiate quantitative and qualitative form of exercise to give appropriate developmentally interventions for children during acquisition of fundamental movement skills. In particular, they suggested integrative neuro-training that is a conceptual exercise training model that incorporates general (e.g. fundamental movement skills) and specific trials (e.g. exercises focused to motor control deficits) with neurocognitive/visual motor feedback to enhance, a wide motor skill development. This could be, also, a good promotion of injury-free physical activity [21].

Another important element to enhance the cognitive level of young soccer players is the intensity of training that induces higher attentional control demands during the match: are recommended the use of technical and tactical drills that focus on the speed-agility under time pressure. Indeed, the increasement of speed of execution (and then the fatigue) leads to strong modification on the attentional level and on coordination skills [7] [22].

Thus, we can assume (the schema in Figure 1 summarizes the relationships) that selective attention and the decision making become fundamental for a modern soccer player: indeed, processing a large amount of information and the selection of only the useful's/important allowed accurate decisions [8]. In other word; soccer players have to take decisions very quickly, choosing the best solution

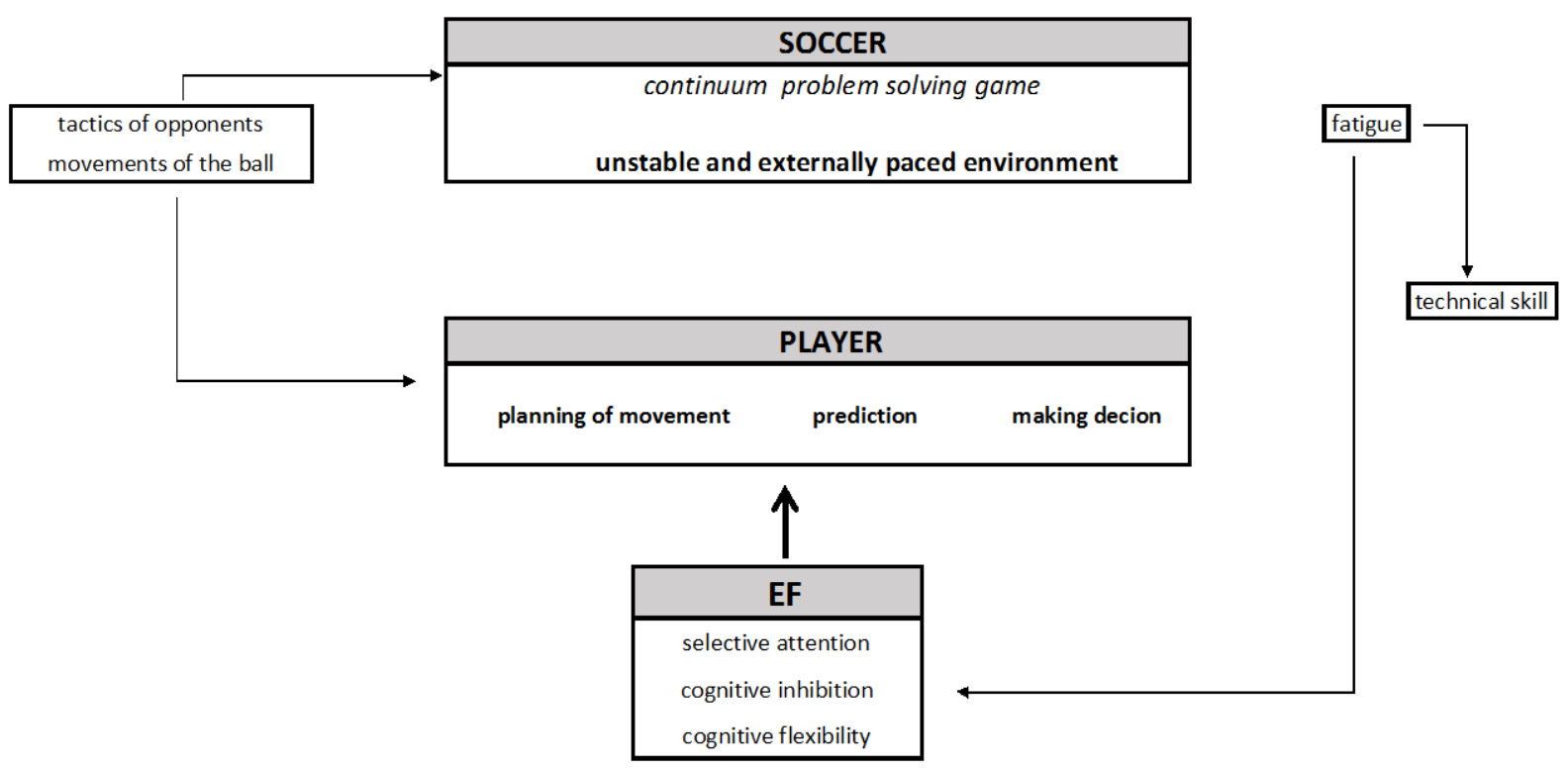

Figure 1. Relations between soccer player and executive function. 


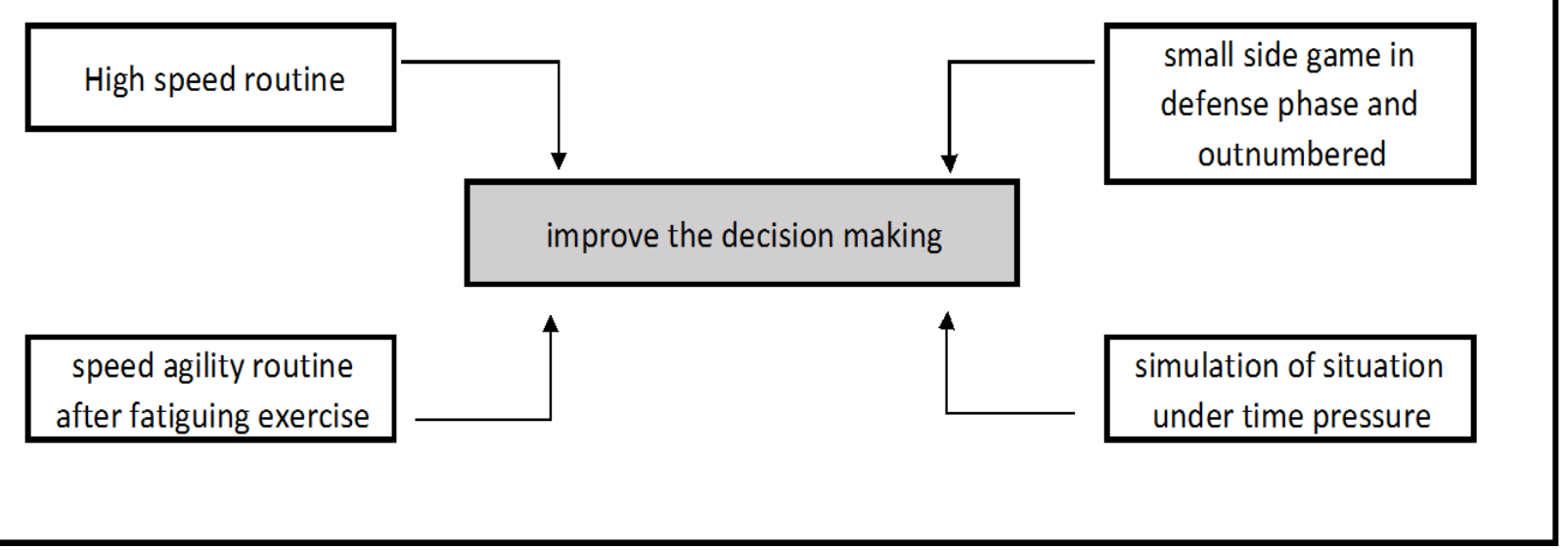

Figure 2. Suggestions to improve the decision making.

in front of different problem-solving environment (such as different possibility of choice), anticipate the consequences and, in general, move their self before the ball [1] [2].

In particular, an important underlying regards the cognitive expertise required for soccer game. These can be divided into two subdomains: tactical knowledge (which involves the ability to apply the most appropriate strategy due to a given situation) and the intuitive process to "scovered" the opponent tactic [5].

Indeed, in top level soccer players the analysis of the environment, the concentration, the problem solving attitude, the speed in decision making and, obviously, the technical skills are very fundamental [21].

\section{Conclusions}

A good suggestion to improve the training in soccer regards intense environment exercise where the information quickly changes [7]: indeed, actually, the evolution of the game is very intensive and rapid.

In particular, the authors consider the exercise with "different-color discrimination" not so useful because in soccer this kind of FE is largely reduced by different colors of the t-shirt of the teams, and emphasize the speed-agility exercise or the small side games where the pressure constrains rapid decision making (obviously, supported by high technical skills). Figure 2 is a summary of good indication to improve the EF in soccer game.

Considering the life span, the exercises focusing on EF will lead the youngs to leave stereotype about tactics and improve the promotion of original "thinking" about real-context problem.

Soccer coaches are recommended to make use of technical and tactical drills that focus on the agility under time pressure to induce high attentional control and EF. 


\section{References}

[1] Wein, H. (2004) Developing Game Intelligence in Soccer. Reedswain, Spring City.

[2] Wein, H. (2007) Developing Youth Football Players: Tap the Full Potential of Your Young Footballers Human Kinetics: Champain (IL). Human Kinetics Publishers, Champaign.

[3] Espy, K.A. (2004) Using Developmental, Cognitive, and Neuroscience Approaches to Understand Executive Control in Young Children. Developmental Neuropsychology, 26, 379-384. https://doi.org/10.1207/s15326942dn2601_1

[4] Fransen, J., Lovell, T.W., Bennett, K.J., Deprez, D., Deconinck, F.J., Lenoir, M. and Coutts, A.J. (2017) The Influence of Restricted Visual Feedback on Dribbling Performance in Youth Soccer Players. Motor Control, 21, 158-167. https://doi.org/10.1123/mc.2015-0059

[5] Baláková, V., Boschek, P. and Skalíková, L. (2015) Selected Cognitive Abilities in Elite Youth Soccer Players. Journal of Human Kinetics, 30, 267-276. https://doi.org/10.1515/hukin-2015-0129

[6] Wang, C.H., Chang, C.C., Liang, Y.M., Shih, C.M., Chiu, W.S., Tseng, P., Hung, D.L., Tzeng, O.J., Muggleton, N.G. and Juan, C.H. (2013) Open vs. Closed Skill Sports and the Modulation of Inhibitory Control. PloS One, 8, e55773. https://doi.org/10.1371/journal.pone.0055773

[7] Vestberg, T., Gustafson, R., Maurex, L., Ingvar, M. and Petrovic, P. (2012) Executive Functions Predict the Success of Top-Soccer Players. PLoS One, 7, e34731. https://doi.org/10.1371/journal.pone.0034731

[8] Vestberg, T., Reinebo, G., Maurex, L., Ingvar, M. and Petrovic, P. (2017) Core Executive Functions Are Associated with Success in Young Elite Soccer Players. PLoS One, 12, e0170845. https://doi.org/10.1371/journal.pone.0170845

[9] Diamond, A. (2013) Executive Functions. Annual Review of Psychology, 64, 135-168. https://doi.org/10.1146/annurev-psych-113011-143750

[10] Hughes, C. and Graham, A. (2002) Measuring Executive Functions in Childhood: Problems and Solutions. Children and Adolescent Mental Health, 7, 131-142. https://doi.org/10.1111/1475-3588.00024

[11] Miley, W.M. and Spinella, M. (2007) Correlations among Executive Function Scales and Positive Psychological Attributes in College Students. Psychological Reports, 100, 24-26. https://doi.org/10.2466/pr0.100.1.24-26

[12] Geertsen, S.S., Thomas, R., Larsen, M.N., Dahn, I.M., Andersen, J.N., Krause-Jensen, M., Korup, V., Nielsen, C.M., Wienecke, J., Ritz, C., Krustrup, P. and Lundbye-Jensen, J. (2016) Motor Skills and Exercise Capacity Are Associated with Objective Measures of Cognitive Functions and Academic Performance in Preadolescent Children. PLoS One, 11, e0161960. https://doi.org/10.1371/journal.pone.0161960

[13] Chang, Y.K., Tsai, Y.J., Chen, T.T. and Hung, T.M. (2013) The Impacts of Coordinative Exercise on Executive Function in Kindergarten Children: An ERP Study. EXperimental Brain Research, 225, 187-196. https://doi.org/10.1007/s00221-012-3360-9

[14] Tomporowski, P.D. (2017) Exercise and Cognition. Pediatric Exercise Science, 29, 31-34. https://doi.org/10.1123/pes.2017-0016

[15] Best, J.R. and Miller, P.H. (2010) A Developmental Perspective on Executive Function. Child Development, 81, 1641-1660. https://doi.org/10.1111/j.1467-8624.2010.01499.x 
[16] Moreno, J., Esposito, S., Lopez, J.F. and Campos, I.M. (2012) Spanish Academy Soccer Coaching. Abfutbol, Madrid.

[17] Miller, B.T. and Clapp, W.C. (2011) From Vision to Decision: The Role of Visual Attention in Elite Sports Performance. Eye \& Contact Lens, 37, 131-139. https://doi.org/10.1097/ICL.0b013e3182190b7f

[18] Badin, O.O., Smith, M.R., Conte, D. and Coutts, A.J. (2016) Mental Fatigue: Impairment of Technical Performance in Small-Sided Soccer Games. International Journal of Sports Physiology and Performance, 11, 1100-1105. https://doi.org/10.1123/ijspp.2015-0710

[19] Rozand, V., Pageaux, B., Marcora, S.M., Papaxanthis, C. and Lepers, R. (2014) Does Mental Exertion Alter Maximal Muscle Activation? Frontiers in Human Neuroscience, 8, 1-10. https://doi.org/10.3389/fnhum.2014.00755

[20] Myer, G.D., Faigenbaum, A.D., Edwards, N.M., Clark, J.F., Best, T.M. and Sallis, R.E. (2015) Sixty Minutes of What? A Developing Brain Perspective for Activating Children with and Integrative Exercise Approach. British Journal of Sports Medicine, 49, 1510-1516. https://doi.org/10.1136/bjsports-2014-093661

[21] Cortis, C., Tessitore, A., Perroni, F., Lupo, C., Pesce, C., Ammendolia, A. and Capranica, L. (2009) Interlimb Coordination, Strength, and Power in Soccer Players across the Lifespan. Journal of Strength and Conditioning Research, 23, 2458-2466. https://doi.org/10.1519/JSC.0b013e3181bc1b39

[22] Reilly, T., Williams, A.M., Nevill, A. and Franks, A. (2009) A Multidisciplinary Approach to Talent Identification in Soccer. Journal of Sports Science, 18, 668-676. 